\title{
Diş Hekimlerinin Tıbbi Atık Yönetimi Konusundaki Bilgi, Tutum ve Davranışlarının Araştırılması
}

\author{
Investigation of Knowledge, Attitudes and Behaviors of Dentists \\ on Medical Waste Management \\ Merve Köseoğlư ${ }^{1}$, Hande Toptan ${ }^{2}$, Selma Altındiş ${ }^{3}$ \\ ${ }^{1}$ Sakarya Üniversitesi Diş Hekimliği Fakültesi, Protetik Diş Tedavisi Anabilim Dal, Sakarya, Türkiye \\ ${ }^{2}$ Sakarya Üniversitesi Tip Fakültesi, Temel Tip Bilimleri Bölümü Tibbi Mikrobiyoloji Anabilim Dalı, Sakarya, Türkiye \\ ${ }^{3}$ Sakarya Üniversitesi İsletme Fakültesi Sağlı Yönetimi Bölümü, Sakarya, Türkiye \\ Yazışma Adresi / Correspondence: \\ Merve Köseoğlu \\ Mithatpaşa Mah. Adnan Menderes Cad. No: 122/B Adapazarı/SAKARYA \\ T: +9026429541 17 E-mail: mervekoseoglu89@gmail.com \\ Geliş Tarihi / Received : 15.11.2018 Kabul Tarihi / Accepted : 25.03.2019
}

Bu çalışma, 1. Uluslararası Dental ve Oral Enfeksiyonlar Kongresi’nde (7-9 Eylül 2018, Sakarya, Türkiye) poster olarak sunulmuştur. Orcid :

Merve Köseoğlu https://orcid.org/0000-0001-9110-9586

Hande Toptanhttps://orcid.org/0000-0001-6893-8490

Selma Altındișhttps://orcid.org/0000-0003-2805-5516

\footnotetext{
$\ddot{O} z$

Amaç Bu çalışmanın amacı, diş hekimlerinin tıbbi atıkların toplanması ve bertaraf edilmesi konusundaki bilgi, tutum ve davranışlarının incelenmesidir.. ( Sakarya Tip Dergisi 2019, 9(2):245-252 )

Gereç ve Gerekli etik ve idari izinler alındıktan sonra 86 diş hekiminin katılımı ile gerçekleştirilen çalışma kapsamında, katılımcılara 19 soruluk dijital anket uygulanmıştır. Elde Yöntemler edilen veriler, tanımlayıcı istatistiksel metodlar ve Ki-kare testi kullanılarak analiz edilmiștir. İstatistiksel anlamlllık $\mathrm{p}<0,05$ düzeyinde değerlendirilmiştir.

Bulgular Calısmaya katılan dis hekimlerinin \%61,22' sinin kadın, \%38,79' unun erkek, \%51,81' inin 23-29 yas arasında, \%37,28' inin kamu hastanesinde çalışmakta olduğu ve $\% 58,33^{\prime}$ ünün herhangi bir branșta uzmanlığının olmadığı belirlenmiștir. Katılımcıların \%70,61' inin tıbbi atık yönetimi konusunda eğitim aldıkları, \%68,21' inin atıkları doğru renkli torbalara atmaya dikkat ettikleri, \%71,77’ sinin çalıștıkları kurumda atıkların ayrı poşetlerde toplandığı, \%63,09' unda ayrı depolandığı, \%78,63' ünde kesici ve delici atıkların darbeye dayanıklı tıbbi atık kutularında muhafaza edildiği belirlenmişken hekimlerin $\% 81,23$ 'ü biyotehlike amblemini doğru tanımlamıştır.

Sonuç Tıbbi atıkların kontrolü yönetmeliği konusunda eğitimler verilerek hekimlerin bilgi, tutum ve davranışlarının olumlu yönde etkilenmesi önerilmektedir.

Anahtar Diş hekimliği; Tibbi atık; Tibbi atık imhası

Kelimeler

Abstract

Objective The aim of this study was to examine the knowledge, attitudes and behaviors of dentists on collection and disposal of medical wastes. ( Sakarya Med J 2019, 9(2):245-252).

Materials A digital questionnaire consists of 19 questions was applied to 86 dentists after ethical permissions. The data were analyzed using descriptive statistical methods and Chi-square test. Statistical and Methods $\quad$ significance was assessed at $p<0,05$.

Results According to results of this study, 61,22\% of the participating dentists were women, 38,79\% were men, 51,81\% were between $23-29$ years, 37,28\% were employed in public hospitals, and $58,33 \%$ did not specialised in any branch. $70.61 \%$ of participant dentists stated that they have received training in medical waste management, $68,21 \%$ said that they threw waste in the right colored bags. According to dentists' statements 71,77\% of waste were collected separately, 63,09\% of them were stored separately, 78,63\% of sharp instruments were kept in special waste bins in their dental offices.

Conclusion It is recommended that the knowledge, attitudes and behaviors of physicians should be affected positively by giving trainings on of medical waste management.

Keywords Dentistry; Medical Waste; Medical Waste Disposal
} 


\section{GIIRIŞ}

İnsan ve hayvanların tanı, tedavi ve bağışıklaması sırasında oluşan ve araştırma laboratuvarlarında üretilen bütün atıklar tıbbi atık olarak tanımlanmaktadır. ${ }^{1}$

Tibbi atıkların bertarafinda uluslararası standart genel ilkeler olduğu gibi, ülkelerin kendi belirledikleri yönetmelikler de mevcuttur. ${ }^{2}$ Ülkemizde yayınlanan tıbbi atık kontrol yönetmeliğine göre, sağlık kuruluşlarından kaynaklanan atıklar; evsel nitelikli atıklar, tıbbi atıklar, tehlikeli atıklar ve radyoaktif atıklar olarak sinıflandırılmaktadır. Başta mutfak, bahçe ve idari birimlerden kaynaklanan kontamine olmamış atıklardan oluşan evsel nitelikli atıklar, siyah renkli plastik torbalarda toplanmalıdır. Ambalaj atığı, mavi renkli plastik torbalarda toplanması gereken, kontamine olmamış, tekrar kullanılabilir, geri dönüştürülebilir ve geri kazanılabilir plastik, metal, cam ve kağıt-karton atıklarıdır. Enfeksiyöz, patolojik ve kesici-delici atıklardan oluşan tıbbi atıklar, her iki yüzünde "Uluslararası Biyotehlike" amblemi ile "Dikkat Tibbi Atık" ibaresini taşıyan kırmızı renkli plastik torbalarda toplanmalıdır. Kesici ve delici özelliği olan atıklar diğer tıbbi atıklardan ayrı olarak üzerinde "Dikkat! Kesici ve Delici Tibbi Atık" ibaresi taşıyan plastik veya aynı özelliklere sahip lamine kartondan yapılmış kutu veya konteynerler içinde toplanmalıdır. Tehlikeli atıklar, genotoksik, farmasötik ve kimyasal atıklar ile ağır metal içeren atıkları (amalgam atıkları) ve basınçı kapları içerir. Radyoaktif atıklar Türkiye Atom Enerjisi Kurumu mevzuatı doğrultusunda bertaraf edilen atıklardir. $^{3,4}$

Tibbi atıklar, özellikleri nedeniyle hastalıklara ve yaralanmalara neden olabilmekte ve toplanma, taşınma ve bertaraf etmede çeşitli zorluklar oluşturmaktadır. ${ }^{5}$ Tibbi atıkların zararlı etkilerinden, ilk başta sağlık çalışanları ve hastalar, bu atıkları toplayan ve bertaraf eden personel etkilenmektedir. ${ }^{6}$ Tibbi atıkların bertarafındaki sorunlarda ve çevre kirliliği durumunda halk da risk altına girmektedir. $^{7}$
Sağlık çalışanları, sağlık hizmetlerinin sonucunda oluşan atıkların toplanması, geçici depolama alanlarına taşınması, depolanması ve belediye görevlilerine tesliminden sorumludur. Tibbi atık yönetiminin etkin bir şekilde yapılabilmesi için, sağlık çalışanlarının bu alanda bilgili olması son derece önemlidir. ${ }^{3,4}$

Bu çalışmanın amacı, diş hekimlerinin tıbbi atıkların toplanması ve bertaraf edilmesi konusundaki bilgi, tutum ve davranışlarının incelenmesidir. Çalışmanın hipotezi ise, farklı demografik özelliklere sahip diş hekimlerinin tıbbi atık yönetimine ilişkin bilgi, tutum ve davranışlarının farklı olduğudur.

\section{GEREÇ ve YÖNTEMLER}

Araştırma, sağlık kuruluşlarında görev yapan diş hekimlerinin tıbbi atık yönetimi konusundaki değerlendirmelerini ölçmeye yönelik kesitsel tipte tanımlayıcı araştırmadır. Sakarya Üniversitesi Tip Fakültesi'nden 7152473/050.01.04/209 nolu etik kurul onayı alınarak çalışmaya başlanmıştır. Anket çalışması, Temmuz- Ağustos 2018 tarihleri arasında, Türkiye genelinde, 85 diş hekiminin katılımı ile gerçekleştirilmiştir.

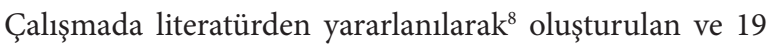
sorudan oluşan bir anket kullanılmıştır. Diş hekimlerinden, kendilerine yöneltilen anket sorularını bireysel ve gönüllü olarak cevaplamaları istenmiştir.

Çalışma kapsamında, diş hekimlerine tıbbi atık bilgi düzeylerini ölçen 5 adet soru sorulmuştur. Çalısmaya katılan diş hekimlerinin sorulara verdiği her bir doğru cevap için 20 puan, yanlıs cevap için 0 puan verilmiştir, soruların hepsine doğru yanıt verilebildiği takdirde elde edilecek maksimum puan \%100 olacak şekilde hesaplanmıştır. Böylece çalısmaya katılan her bir diş hekimi için bir puan elde edilmistir. Hesaplanan puan toplamlarına göre 4 grup yapılmıştır. \%25 'den az puan alanların bilgi düzeyleri "düşük”, \%25 puan ile \%50 puan arası alanların bilgi düzeyi “orta”, 50 puan ile 75 puan arası alanların bilgi düzeyleri 
“iyi”, \%75 ile \%100 puan arası alanların bilgi düzeyleri “yüksek” sınıflandırılmıştır.

İstatistiksel analiz SPSS 23,0 (SPSS Inc., Chicago, IL, ABD) programı kullanılarak yapılmıştır. Tanımlayıcı istatistikler sonucu sayı ve yüzde olarak verilmiştir ve gruplar arası farklılıkları karşılaştırmak için ki-kare testi kullanılmıştır. İstatistiksel anlamlılık düzeyi $\mathrm{p}<0,05$ olarak belirlenmiştir.

\section{BULGULAR}

Çalışma sonucunda, ankete katılan diş hekimlerinin \%61,22' sinin kadın, \%38,79' unun erkek; büyük bir kısmının (\%51,81) 23-29 yaş aralığında; 1-5 yıl mesleki deneyime sahip $(\% 58,33)$; kamu hastanesinde çalışmakta $(\% 37,28)$ ve günlük 10 kişiden az sayıda $(\% 45,12)$ hasta baktığı belirlenmiştir. Ayrıca, katılımcı diş hekimlerinin \%58,33' ünün herhangi bir branşta uzmanlığı yokken, \%67,14' ünün pratisyen diş hekimi olduğu belirlenmiştir. Türkiye'nin farklı bölgelerinden ankete katılan diş hekimlerinin demografik özellikleri Tablo 1'de gösterilmiştir.
Çalışmaya katılan diş hekimlerinin \%70,61' i tıbbi atık yönetimi konusunda eğitim aldıklarını, \%29,39’ u ise almadıklarını belirtmişlerdir.

Hekimlerin \%85,89'u infeksiyöz karakter taşımayan kağıt, karton, cam, metal, plastikler, pet şişe, teneke kutu vb. atıklar için mavi renkli ambalaj atığı torbası kullanılması gerektiğini belirtirken, \%2,44’ü gerekmediğini ve \% 11,67'si ise bu konuda bilgilerinin olmadığını belirtmişlerdir.

Hekimlerin \%89,37'si infekte olmamış mutfak atıkları, büro atıkları, bahçe atıkları, naylon torba vb. atıklar için siyah renkli evsel atık torbası kullanılması gerektiğini düşünürken, \%1,21'i bunun gerekli olmadığını belirtmiş, \%9,42'si ise bu konuda bilgilerinin olmadığını bildirmişlerdir.

Hekimlerin \%85,94’ü kan, kan ürünleri, enfeksiyöz vücut sıvılarıyla kontamine olmuş nesneler, çekilmiş diş, otopsi parçaları, bistüri, enjektör iğnesi gibi atıklar için kırmızı

\begin{tabular}{|l|l|l|l|}
\hline \multicolumn{4}{|l|}{ Tablo 1. Çalışmaya katılan diş hekimlerinin demografik bilgileri } \\
\hline Yaş aralığı (yıl) & Kişi Sayısı (Yüzde) & Cinsiyet & Kişi Sayısı (Yüzde) \\
\hline $23-29$ & $44(51,81)$ & Kadın & $52(61,22)$ \\
\hline $30-39$ & $27(31,83)$ & Erkek & $33(38,78)$ \\
\hline $40-49$ & $9(10,58)$ & Akademik Unvan & Kişi Sayısı (Yüzde) \\
\hline 50 ve üzeri & $5(5,87)$ & Pratisyen Diş Hekimi & $57(67,14)$ \\
\hline Mesleki Deneyim (yıl) & Kişi Sayısı (Yüzde) & Uzman / Dr Diş Hekimi & $23(27,08)$ \\
\hline $1-5$ & $44(51,83)$ & Dr. Öğretim Üyesi & $3(3,53)$ \\
\hline $6-10$ & $19(22,44)$ & Doçent & $0(0,00)$ \\
\hline $11-15$ & $10(11,77)$ & Profesör & $2(2,41)$ \\
\hline 15 yıldan fazla & $14,1(12,02)$ & Çalıştıkları Kurum & Kişi Sayısı (Yüzde) \\
\hline Uzmanlık Alanı & Kişi Sayısı (Yüzde) & Kamu Hastanesi & $31(37,28)$ \\
\hline Uzmanlığı Yok & $49(58,33)$ & Üniversite Hastanesi & $25(30,12)$ \\
\hline Ağız Diş Çene Cerrahisi & $2(2,41)$ & Özel Poliklinik & $14(16,93)$ \\
\hline Ağız Diş Çene Radyolojisi & $2(2,41)$ & Özel Muayenehane & $13(15,67)$ \\
\hline Diş Hastalıkları ve Tedavisi & $6(7,14)$ & Günlük Hasta Sayısı & Kişi Sayısı (Yüzde) \\
\hline Endodonti & $3(3,62)$ & 10 kişiden az & $37(45,12)$ \\
\hline Ortodonti & $3(3,62)$ & $11-20$ kişi & $17(20,68)$ \\
\hline Pedodonti & $3(3,62)$ & $21-30$ kişi & $18(22,01)$ \\
\hline Periodontoloji & $4(4,79)$ & 30 kişiden fazla & $10(12,24)$ \\
\hline Protetik Diş Tedavisi & $12(14,29)$ & & \\
\hline
\end{tabular}


renkli plastik torba kullanılması gerektiğini düşünürken, \%8,19’u bunun gerekli olmadığını belirtmiş ve \%5,87'si bu konu hakkında bilgi sahibi olmadığını bildirmişlerdir.

Mevcut çalışmanın sonuçlarına göre, katılımcıların \%81,23'ü biyotehlike amblemini doğru tanımlamıştır. Ancak katılımcıların \%30,89'u tıbbi atıkların biriktirildiği kapaklı konteyner, kap, kovanın içerisinde en fazla ne kadar zaman bekletilebileceğini doğru cevaplamışlardır.

Mevcut çalışmanın sonuçlarına göre, diş hekimlerinin tıbbi atık bilgi sorularına doğru cevap verme yüzdeleri, bireylerin cinsiyeti $(p=0,690)$, yaşı $(p=0,493)$, mesleki deneyimi $(\mathrm{p}=0,676)$, akademik ünvanı $(\mathrm{p}=0,438)$, uzmanlık alanı $(\mathrm{p}=0,593)$ ve günlük baktıkları hasta sayısına $(\mathrm{p}=0,613)$ göre istatistiksel olarak anlamlı farklılık göstermezken; çalıştıkları kurum ( $\mathrm{p}=0,039)$ ve tıbbi atık eğitimi alıp almamalarına göre $(\mathrm{p}=0,028)$ farklılık göstermektedir. Çalışmada, literatürden yararlanılarak, 50 puan ile 75 puan arası alanların bilgi düzeyleri “iyi”, \%75 ile \%100 puan arası alanların bilgi düzeyleri "yüksek" olarak sınıflandırılmıştır. ${ }^{9}$ Özel polikliniklerde çalışan ve tıbbi atık eğitimi almayan diş hekimlerinin bilgi düzeyleri “iyi” bulunurken, diğer grupların bilgi düzeyleri "yüksek" bulunmuştur. Çalışmaya katılan tüm diş hekimlerinin \%85,98'i tıbbi atık bilgi düzeyini ölçen soruları doğru cevaplamıştır. Bu nedenle, tüm diş hekimlerinin ortalama bilgi düzeyi "yüksek" bulunmuştur (Tablo 2).
Katılımcı diş hekimlerinin \%68,21'i her zaman, \%19,97'si sıklıkla, \%7,13'ü bazen atıkları doğru renkli torbalara atmaya dikkat ettiklerini, \%4,69'u ise hiçbir zaman dikkat etmediklerini bildirmişlerdir. Hekimlerin \%32,88'i her zaman, \%34,08'i sıklıkla, \%23,51'i bazen atıkları yanlış torbalara attıkları zaman iş arkadaşlarını uyardıklarını, \%9,43'ü ise hiçbir zaman dikkat etmediklerini belirtmişlerdir.

Diş hekimlerinin tıbbi atıkları doğru torbalara atma oranları cinsiyet $(\mathrm{p}=0,609)$, yaş $(\mathrm{p}=0,532)$, mesleki deneyim $(\mathrm{p}=0,404)$, uzmanlık alanı $(\mathrm{p}=0,721)$, akademik unvan $(\mathrm{p}=0,228)$, çalıştıkları kurum $(\mathrm{p}=0,272)$ ve günlük bakılan hasta sayısına ( $\mathrm{p}=0,441)$ göre farklılık göstermezken; tıbbi atık kontrolü konusunda eğitim alan diş hekimleri, atıkları doğru torbaya atmaya istatistiksel olarak anlamlı düzeyde $(p=0,002)$ daha fazla dikkat ettiklerini belirtmişlerdir (Tablo 3).

Diş hekimlerinin atık ayrımına dikkat etmeyen iş arkadaşlarını uyarma oranları cinsiyet $(\mathrm{p}=0,609)$, yaş $(\mathrm{p}=0,136)$, mesleki deneyim $(p=0,195)$, uzmanlık alanı $(p=0,214)$, akademik unvan $(\mathrm{p}=0,432)$, çalıştıkları kurum $(\mathrm{p}=0,432)$ ve günlük bakılan hasta sayısına $(\mathrm{p}=0,214)$ göre farklılık göstermezken; tıbbi atık konusunda eğitim alan diş hekimlerinin oranı, eğitim almayanlardan istatistiksel olarak anlamlı düzeyde daha yüksek $(\mathrm{p}=0,037)$ bulunmuştur (Tablo 3).

\begin{tabular}{|c|c|c|c|}
\hline & Kişi Sayısı (Yüzde) & $\mathrm{P}$ değeri & Bilgi Düzeyi \\
\hline \multicolumn{4}{|l|}{ Çalıştıkları Kurum } \\
\hline Kamu Hastanesi & $30(\% 96,89)$ & \multirow{4}{*}{$0,039^{*}$} & Yüksek \\
\hline Üniversite Hastanesi & $24(\% 96,03)$ & & Yüksek \\
\hline Özel Poliklinik & $9(\% 66,67)$ & & İyi \\
\hline Özel Muayenehane & $11(\% 85,72)$ & & Yüksek \\
\hline \multicolumn{4}{|l|}{ Tibbi atık eğitimi } \\
\hline Eğitim alan & $55(\% 91,73)$ & \multirow{3}{*}{$0,028^{*}$} & Yüksek \\
\hline Eğitim almayan & $19(\% 73,11)$ & & İyi \\
\hline Toplam & $74(\% 85,98)$ & & Yüksek \\
\hline
\end{tabular}


Sakarya Tip Dergisi 2019;9(2):245-252

KöSEOĞLU ve Ark. Diş Hekimliğinde Tibbi Atık Yönetimi

Tablo 3. Atıkları doğru torbaya atan ve atıklarını yanlış torbaya atan iş arkadaşlarını uyaran diş hekimlerinin tıbbi atık eğitimine göre karşılaştırılması

\begin{tabular}{|c|c|c|c|c|}
\hline & \multicolumn{2}{|c|}{ Atıkları doğru torbaya atanlar } & \multicolumn{2}{|c|}{ İş arkadaşlarını uyaranlar } \\
\hline & Sayı (Yüzde) & $P$ değeri & Sayı (Yüzde) & $P$ değeri \\
\hline \multicolumn{5}{|l|}{ Tıbbi Atık Eğitimi } \\
\hline Eğitim alan & $42(\% 70,69)$ & \multirow{2}{*}{$0,002^{*}$} & $20(\% 33,59)$ & \multirow{2}{*}{$0,037^{\star}$} \\
\hline Eğitim almayan & $16(\% 63,78)$ & & $8(\% 30,92)$ & \\
\hline Toplam & $58(\% 68,21)$ & & $28(\% 32,88)$ & \\
\hline
\end{tabular}

Çalışmaya katılan hekimlerin \%71,77’si her zaman, \%14,11'i sıklıkla, \%12,88'i bazen çalıștıkları kurumda, evsel, ambalaj ve tıbbi atıklar ayrı poşetlerde toplandığını, \%1,24'ü hiçbir zaman toplanmadığını belirtmişlerdir. Hekimlerin \%63,09' u her zaman, \%16,72'si sıklıkla, \%13,11'i bazen çalıştıkları kurumda, personel tarafından ünitelerden toplanan atıklar sınıflarına göre ayrım yapılarak depolandığını, \%7,08'i hiçbir zaman depolanmadığını bildirmişlerdir. Katılımcı diş hekimlerinin \%78,63 'ü her zaman, \%17,86'sı sıklıkla, \%3,61'i bazen çalıştıkları kurumda, dental tedaviler esnasında kullanılan kesici ve delici atıklar darbeye dayanıklı tıbbi atık kutularında muhafaza edildiğini belirtmişlerdir.

Tibbi atıkların sınıfların ayrılarak toplanma oranları cinsiyet $(p=0,743)$, yaş $(p=0,359)$, mesleki deneyim $(p=0,108)$, uzmanlık alanı $(\mathrm{p}=0,102)$, akademik unvan $(\mathrm{p}=0,096)$, günlük bakılan hasta sayısına $(\mathrm{p}=0,057)$ göre değişmezken; kamu hastanesinde çalışan $(p<0,001)$ ve tıbbi atık eğitimi alan $(\mathrm{p}=0,002)$ diş hekimlerinin oranları istatistiksel olarak anlamlı düzeyde daha yüksek bulunmuştur (Tablo 4).

Tibbi atıkların sınıfların ayrılarak depolanma oranları kamu hastanesinde çalışan $(p<0,001)$ ve tıbbi atık eğitimi alan $(\mathrm{p}=0,012)$ diş hekimlerinde istatistiksel olarak anlam1 düzeyde daha yüksek bulunurken; yaş $(\mathrm{p}=0,665)$, cinsiyet $(p=0,884)$, mesleki deneyim $(p=0,242)$, akademik unvan $(\mathrm{p}=0,324)$, uzmanlık alanı $(\mathrm{p}=0,330)$, günlük bakılan hasta sayısına $(\mathrm{p}=0,073)$ göre değişmediği belirlenmiştir (Tablo 4).

\begin{tabular}{|c|c|c|c|c|c|c|}
\hline & \multicolumn{2}{|c|}{ Atıkları ayrı toplayanlar } & \multicolumn{2}{|c|}{ Atıkları ayrı depolayanlar } & \multicolumn{2}{|c|}{$\begin{array}{l}\text { Kesici delici atıkları kutuda depo- } \\
\text { layanlar } \\
\end{array}$} \\
\hline & Yüzde & $\mathrm{P}$ değeri & Yüzde & $P$ değeri & Yüzde & $\mathrm{P}$ değeri \\
\hline \multicolumn{7}{|c|}{ Çalıştıkları Kurum } \\
\hline Kamu Hastanesi & $24(\% 75,62)$ & \multirow{4}{*}{$0,000^{*}$} & $20(\% 66,19)$ & \multirow{4}{*}{$0,000^{\star}$} & $26(\% 81,59)$ & \multirow{4}{*}{$0,034^{*}$} \\
\hline $\begin{array}{l}\text { Üniversite Has- } \\
\text { tanesi }\end{array}$ & $18(\% 71,51)$ & & $16(\% 63,32)$ & & $21(\% 80,91)$ & \\
\hline Özel Poliklinik & $9(\% 68,56)$ & & $8(\% 60,89)$ & & $10(\% 75,32)$ & \\
\hline $\begin{array}{l}\text { Özel Muayene- } \\
\text { hane }\end{array}$ & $10(\% 69,33)$ & & $10(\% 61,43)$ & & $11(\% 78,78)$ & \\
\hline Toplam & $61(\% 71,77)$ & & $54(\% 63,09)$ & & $68(\% 78,63)$ & \\
\hline \multicolumn{7}{|l|}{ Tibbi Atık Eğitimi } \\
\hline Eğitim alan & $43(\% 72,48)$ & \multirow{2}{*}{$0,002^{*}$} & $38(\% 64,31)$ & \multirow{2}{*}{$0,012^{*}$} & $48(\% 80,37)$ & \multirow{2}{*}{$0,043^{*}$} \\
\hline Eğitim almayan & $18(\% 69,79)$ & & $16(\% 62,72)$ & & $20(\% 77,32)$ & \\
\hline
\end{tabular}


Kesici delici atıkların diğer atıklardan ayrı, karton kutularda saklanma oranları yaş $(\mathrm{p}=0,859)$, cinsiyet $(\mathrm{p}=0,228)$, uzmanlık alanı $(\mathrm{p}=0,071)$, akademik unvan $(\mathrm{p}=0,496)$, mesleki deneyim $(\mathrm{p}=0,671)$, günlük bakılan hasta sayısına $(p=0,266)$ göre değişmezken; tıbbi atık eğitimi alan $(\mathrm{p}=0,043)$ ve kamu hastanesinde çalışan $(\mathrm{p}=0,034)$ diş hekimlerinin oranları istatistiksel olarak anlamlı düzeyde daha yüksek bulunmuştur (Tablo 4).

\section{TARTIŞMA}

Sağlıkla ilgili girişimler sonrası oluşan atıklar, potansiyel enfeksiyon kaynağı olma riski nedeniyle günlük hayattaki diğer atıklardan farklılık gösterirler. Ancak, sağlık kuruluşları tarafından oluşturulan her atık enfeksiyöz değildir ve doğru bertaraf edilirlerse halk ve çevre sağlığı açısından tehlike oluşturmazlar. ${ }^{2}$ Kontamine atıkların bilinmesi ve ayrımlarının doğru yapılması, hastaların, sağlık çalışanlarının, atıkları toplayan kişilerin, çevrenin ve toplumun, atıkların zararlı etkilerinden korunmasında fayda sağlayacak ve bertaraf işlemlerinin giderlerini ciddi ölçüde azaltacaktır. $^{10}$

Mevcut çalışmanın sonuçlarına göre, hipotezimiz kısmi olarak kabul edilmiştir. Kamu hastanesinde çalışan ve tıbbi atık konusunda eğitim alan diş hekimlerinin bilgi düzeylerinin daha yüksek ve davranışlarının atık kontrol yönetmeliğine daha uygun olduğu bulunurken; diğer demografik özelliklere göre bilgi düzeyi ve tutum değişmemiştir. Bu durumun, kamu hastanelerinde, diş hekimleri ve yardımcı personele, tıbbi atık kontrolü eğitimlerinin belirli aralıklarla verilmesi ve efektif verilen eğitimler sonucunda diş hekimlerinin bilgi, tutum ve davranışlarının olumlu etkilenmesinden kaynaklandığı düşünülmüştür.

İncesu ve Evirgen8 çalışmalarında, ağız ve diş sağlığı çalışanlarının \%88,7'sinin hastane atıkları konusunda eğitim aldığını, \%8'i ise eğitim almadıklarını belirtmiştir. Akbolat ve ark. ${ }^{11}$ sağlık çalışanlarının \%69,6'sının tıbbi atık yönetimi konusunda eğitim aldığını belirtmiştir. Terzi ve ark. ${ }^{12}$ çalışmaları sonucunda, katılımcıların \%80,5'inin tıbbi atık yönetimi konusunda eğitim aldıklarını bildirmişlerdir.

Mevcut çalışmaya katılan hekimlerin \%70,6’sı tıbbi atık yönetimi eğitimi aldıklarını, \% 29,4'ü ise almadıklarını bildirmişlerdir. Çalışmamızdan elde edilen sonuçlar Akbolat ve arknın. ${ }^{11}$ sonuçlarına benzer bulunmuştur.

Akbolat ve ark. ${ }^{11}$ sağlık çalışanlarının tıbbi atık bilgi düzeylerini değerlendirdikleri çalışmalarında, sağlık çalışanlarının \%97,1'inin tıbbi atıkların kırmızı renkli torbalarda toplanması gerektiğini bildiğini, \%62,8’inin evsel atıkların siyah torbalarda, \%61,2'sinin geri dönüştürülebilir atıkların mavi torbalarda toplanması gerektiğini düşündüklerini bildirmişlerdir.

Rahman ve ark. ${ }^{13}$ sağlık kuruluşlarının tıbbi atıkları toplama, depolama ve bertaraf etme yöntemlerini araştırdıkları çalışmalarında, kurumların \%69,2'sinde çöplerin sınıflandırılarak ayrı poşetlerde toplandığını, evsel atıkların \%65,4'ünde siyah poşetlerde, tıbbi atıkların \%57,7'sinde kırmızı poşetlerde toplandığını, kesici-delici tıbbi atıkların \%69,2'sinde özel kaplarda toplandığını belirtmişlerdir. İncesu ve Evirgen ${ }^{8}$ ağız ve diş sağlığı hizmetleri çalışanlarının atıklar konusunda bilgi düzeylerinin belirlenmesini araştırdıkları çalışmalarında, katılımcıların \%51,3'ünün evsel atıkları mavi torbalara, \%43,3'ü siyah torbalara att1ğını belirtmişlerdir.

Mevcut çalışmaya katılan hekimlerin \%85,9'unun ambalaj atıklarının mavi, \%89,4'ünün evsel atıkların siyah, \%85,9'unun tıbbi atıkların kırmızı renkli torbalarda toplanması gerektiğini bildiği anlaşılmıştır. Araştırmamızın sonuçlarına göre, hekimlerin tıbbi atık yönetimi konusundaki bilgi düzeyleri önceki çalışmalardan ${ }^{8,11,13}$ daha yüksek düzeyde bulunmuştur.

Hasçuhadar ve ark. ${ }^{14}$ sağlık personelinin \%97,8'inin tıbbi atıkların uygun bir sekilde atılmasına dikkat ettiğini belirtirken, \%2,2'sinin ise dikkat etmediğini belirtmiştir. Hindistan'da yapılan çalışmada, diş hekimlerinin \%85'inin 
atıkları çeşidine göre farklı renklerde torbalarda muhafaza edilmesi gerektiğini, \%60’ı ise kesici ve delici atıkların özel kutularda saklanması gerektiğini bildiği belirlenmiştir. ${ }^{15}$

Çalışmamızda, ankete katılan diş hekimlerinin \%68,2'si atıkları her zaman doğru renkli torbalara atmaya dikkat ettiğini, \%63,1’i çalıştığı kurumda, personel tarafından ünitelerden toplanan atıkların her zaman sınıflarına göre ayrım yapılarak depolandığını ve \%78,6'sı ise kesici ve delici atıkların her zaman darbeye dayanıklı tıbbi atık kutularında muhafaza edildiğini belirtmişlerdir. Çalışmamızdan elde edilen sonuçlar Hasçuhadar ve arkadaşlarının ${ }^{14}$ sonuçlarından farklılık göstermiştir.

İncesu ve Evirgen ${ }^{8}$ çalışmalarında, biyotehlike sembolünü katılımcıların \%76,7'sinin doğru, \%18,7'sinin ise hatalı tanıdı̆̆ını belirtmişlerdir. Akbolat ve ark. ${ }^{11}$ çalışmasında, katılımcıların \%89,3’ünün biyotehlike amblemini doğru tanıdığını, \%10,7'sinin ise hatalı tanıdığını belirtmişlerdir. Çalışmamızın sonuçlarına göre, katılımcıların \%81,2'si biyotehlike amblemini doğru tanımlamış, \%18,8'i ise yanlış tanımlamıştır.

Mevcut çalışmanın sonucunda, tıbbi atık eğitimi alan ve kamu hastanelerinde çalışan diş hekimlerinin tıbbi atık konusundaki bilgi düzeyleri daha yüksek, tutum ve davranışları daha olumlu bulunmuştur. Bu sonuçtan yola ç1karak, tıbbi atıkların kontrolü yönetmeliği doğrultusunda gerekli tedbirler alınarak ve sağlık çalışanlarına eğitimler verilerek, çalışanlara, hastalara, hasta yakınlarına ve çevreye risk oluşturmadan sağlık hizmetlerinin sürdürülebilmesi önerilmektedir. 
Sakarya Tip Dergisi 2019;9(2):245-252

\section{Kaynaklar}

1. Aktas F. Tibbi ve Tehlikeli Atık Yönetimi. Hastane İnfeksiyonları Dergisi.2014:18(1):99-103. 2. Devrim İ. Atık Yönetimi ve Diş Hekimlĭginde Uygulamaları. Hastane İnfeksiyonları Dergisi. 2011;3(11):169-78.

3. http://www.resmigazete.gov.tr/eskiler/2005/07/20050722-16.htm

4. http://www.resmigazete.gov.tr/eskiler/2017/01/20170125.pdf.

5. Mohee R. Medical wastes characterisation in healthcare institutions in Mauritius. Waste Management. 2005;25(6):575-81.

6. Danchaivijitrmd S, Santiprasitkul S, Tiersuwan S, Naksawas K. Problems in the management of medical waste in Thailand. J Med Assoc Thai. 2005;88(10):140-4.

7. Pruss A, Giroult E, Rushbook P. Safe Management of Wastes from Health-Care Activities.; Geneva: World Health Organization; 1999; 1(1): 2-8.

8. İncesu E, Evirgen H. Ağız ve Diş Sağllğı Hizmetleri Çalışanlarının Atıklar Konusundaki Bilgi Düzeylerinin Belirlenmesi. USAYSAD. 2017;3(1):59-71.

9. Fotedar S, Sharma KR, Sogi GM, Fotedar V, Chauhan A. Knowledge and attitudes about HIV/AIDS of students in HP Government Dental College and Hospital, Shimla, India. J Dent Educ. 2013;77(9):1218-24.

10. Özerol İH. Tibbi Attk Stratejileri Nelerdir? EN/ISO Normları Nelerdir? Avrupa'da Birlik? ABD’nin Yaklasımı? Ülkemizde Durum? In: Gunaydın M, Esen S, Sanic A, Leblebicioglu H, editors. 4 Ulusal Sterilizasyon Dezenfeksiyon Kongresi; Samsun: SIMAD; 2005:434-72.
11. Akbolat $M$, Ișık $O$, Dede C, Çimen M. Sağlık çalıșanlarının tıbbi atık bilgi düzeylerinin değerlendirilmesi. ACU Sağlık Bil Derg. 2011;2(3):131-40.

12. Terzi Ö, Aker S, Sünter AT, Pekșen Y. Hastane Temizlik Elemanları ve Mesleki Enfeksiyon Riski: Bilgi ve Davranışlar Üzerine Bir Çalı̧ma. Turgut Özal Tip Merk Derg. 2009;16(1):7-

13. Rahman S, Açıł Y, Gülbayrak C, Erhan D, Nazher K, Deveci SE. Sağlık Kuruluşlarının Tibbi Atıkları Toplama, Depolama ve Bertaraf Etme Yöntemleri. Firat Sağllk Hizmetleri Dergisi. 2009;4(11):3-14.

14. Hascuhadar M, Kaya HZ, Suna H, Arslan T, Altınkaya S. Ankara Atatürk Eğitim ve Araštırma Hastanesi personelinin tıbbi atık konusunda bilgi düzeyi. Turkish Medical Journal 2007;1(1):138-44.

15. Narang RS, Manchanda A, Singh S, Verma N, Padda S. Awareness of biomedical waste management among dental professionals and auxiliary staff in Amritsar, India, Oral Health Dent Manag 2012;11(4):162-8. 